\title{
Designing Knowledge Management System for Supporting Craftsmen's Collaboration beyond Temporal Boundaries
}

\author{
Mika Yasuoka \\ Japanordic \\ mika@japanordic.com
}

\author{
Sadayo Hirata \\ Shibaura Institute of Technology \\ hirata-s@sic.shibaura-it.ac.jp
}

\begin{abstract}
Knowledge of traditional craft practitioners has been transmitted through demonstration in masterapprentice relations. These rare skills are in danger of being lost due to their low productivity and labor intensiveness in our modern industrialized society. In collaboration with traditional craft practitioners in the metal casting industry, we designed an interactive knowledge management system that captures and passes on distributed tacit knowledge of experts. We found that collaborative social practice with focus on computational alternatives helped craftsmen with limited design knowledge to recognize and reflect upon their own skills, as well as values of the industry. Furthermore, technologically enhanced communication possibilities beyond temporal boundaries encourage craftsmen to conduct seamless skill transfer to the next generation. We discuss how design participation of craftsmen led to mindset changes and argue how their receptive collaboration contributed to the design life cycle of a knowledge management system.
\end{abstract}

\section{Introduction}

Traditional skilled practitioners, who have successively continued to preserve their native creative know-how, are likely to be under-supported in our industrialized society $\mathrm{cf}$. [6,18]. As traditional craft skills have been developed through practice [29], the majority of such skills have been transmitted through demonstration of practice through master-apprentice relations. The apprentice has often learned such artisan skills by carrying out practices under instruction from master craftsmen. However, in our modern society, industrialization and factory automation have pushed such craftwork skills into the background. Today the traditional skills are in danger of being lost due to a lack of successors. Traditional practitioners who have seldom collaborated with others have no other means to externalize their tacit knowledge, skills and experiences [35] than their traditional masterapprentice relations.

This article focuses on Japanese metal casting, which is an endangered traditional skill. Metal casting is often used for complex shapes that are difficult to make using industrial mass production. The casting processes have been known for thousands of years, and some have been integrated into industrial production techniques. For example, modern Japanese casting contributes to the global car industry that requires complex shapes for various advanced vehicle parts.

Since it is complicated to industrialize and automate the casting techniques for mass production, the knowledge has been kept within individual foundries, and developed by skilled craftsmen. The detailed knowledge behind each process has resided in the foundry without documentation and externalization in other media apart from artisanal memory. In the foundry, the tacit knowledge of each metal casting process is distributed among different craftsmen. No single craftsman clearly understands the whole process, which makes the casting process hard to reproduce.

Currently, both aging and economic stagnation in Japan have affected the craft life-cycle. In many Japanese small-scale foundries that produce metal casting products, the aging of craftsmen is an increasing problem, and consequently the accumulated cultural and traditional assets of the technology are in danger of being lost. Sooner or later, the existing artifacts will also be hard to restore due to the lack of skilled practitioners. It is difficult if not impossible to revive old techniques once they are lost, as seen in many other traditional crafts $[1,6,17,18]$. For that reason, it is important to take countermeasures to secure the maintenance of skills while the traditional craft practitioners are still active.

Considering the current situation, a knowledge management system has a huge potential to maintain and transmit traditional craft knowledge to the next generation. However, there are challenges regarding passing on traditional techniques in digital means. First, the craftsmen are proud of their own skills and knowledge, so they often hesitate to share and externalize their mastery with others $[27,36]$. They 
value the apprenticeship system - learning by doing and succession to the next generation - that was common in the traditional craft world. Second, practically speaking, craftsmen often think that it is difficult to document such tacit expert knowledge as "we know more than we can tell" [24]. Last, but not least, Japanese craftsmen in metal casting have hardly any experience in collaborating and preserving their knowledge through externalization and digitalization [21,37]

This paper has the following ideas as contributions to the debate. First, using metal casting craftsmen as an example, we investigate how we can support precious traditional crafts and their tacit knowledge, supported by computational artifacts [14-16,38]. Specifically, we design an interactive knowledge management system for metal casting craftsmen by exploring what kind of support can be valuable for them. Second, the paper examines interaction and collaboration with and among craftsmen, which extends the design life cycle of the knowledge management system beyond temporal boundaries in a Japanese craft tradition context.

This paper first introduces context around crafts and discusses related works. This is followed by an introduction to our design case with a Small and Medium-sized Enterprise (SME). Then, we report findings and analyze results, and finally conclude by reflecting on our experiences.

\section{Research Context}

Before introducing related works, this section briefly introduces two current forms of knowledge sharing and transfer in traditional crafts domain.

\subsection{Learning through Educational Programs}

In Europe, some fundamental traditional craft techniques have been integrated into formal craftsmen educational programs. Most craft work in the 19th and early 20th centuries were carried out either in craft workshops or in conservation workshops at major museums [1,17,18] Training was conducted in apprentice-master relations in each individual workshop rather than as formal training [16,31]. Inspired by the international rescue collaboration regarding the damage caused by the tragedy of the River Arno flood in Florence in 1966, quite a few European countries started to establish Schools of Conservation for transmitting craft knowledge to future generations. Nowadays, many related schools provide higher craft education such as masters and Ph.D programs, and promote academic research on conservation and preservation of cultural and traditional crafts $[1,16,31]$.

Currently, fundamental traditional crafts techniques are often acquired in combination with academic learning and in-depth field training in many Western countries $[1,16,17]$. Such craft skills and techniques acquired at schools have several unique characteristics. First, knowledge is systematized through structuring and ordered according to a number of principles. Based on these principles, novice apprentices learn craft skills together with formal externalized processes and domain-specific jargon and expressions. This helps establish common ground in a Community of Practice (CoP) $[4,13,19]$. Second, the crafts skills and knowledge secure a base for knowledge accumulation. Educational institutions play a role in accumulating, disseminating and improving skills, which are passed down to future generations as shared knowledge [19]. Furthermore, learning and discovery in individual crafts studio are disseminated to wider audiences through academic papers and workshops [17]. In this way, design life cycle is maintained, and the craft knowledge is transferred to the public domain rather than just residing in the industrial craftsmen's private domain.

\subsection{Learning without Educational Programs}

The majority of Asian countries kept their traditional ways rather than collaborating and establishing a formal educational environment for craft techniques $[6,10]$. Consequently, many craft techniques and skills are sustained mainly through long-term field experience in practice. In current traditional craft domains, official documentation has rarely been made, and the need for preservation and documentation is often not widely recognized. Even if externalized documentation exists, it is hardly organized and the knowledge behind the processes has not been shared beyond small groups of CoP [19]. When a collective education does not exist, the characteristics of poorly distributed tacit knowledge, endangered techniques, and conservation value become apparent.

Distributed tacit knowledge. The production processes of traditional crafts are fragmented, invisible, and distributed across individuals. Each process requires specialized skills that are acquired as tacit knowledge among craftsmen through long-term practice.

Endangered techniques. Influenced by the introduction of factory automation in SMEs [21], traditional production techniques have been disappearing [37]. Repair of legacy tools and artifacts 
is often treated with shortsighted "quick-and-dirty" solutions due to their perceived economic efficiency.

Conservation value. When repairing damage or deterioration of craftwork, craftsmen choose one repair policy. One way is reproduction of the manufacture of the time, while another is maintenance of the current state by regarding aging as part of the craft [23]. To select one repair policy, consecutive information including the change of the climate and the external environment from the time of manufacture to the present, and compatibility with current materials and chemicals etc. has become the basis for decision making. For repair, only limited records have been made since documentation is not widely valued in the craft world.

No matter what kind of trajectories people experience in order to become a master, whether studies in schools or fields, craftsmen usually value learning in practice the most. Those educated in schools experience field practice as school projects with fundamental crafts skills from textbooks. Later, when they graduate, they start to accumulate their field experiences in practice, improve their skills and acquire further performative understanding. Educated craftsmen still may value their own hands-on experiences and senses when making decisions [1, $17,31]$

\section{Related Works}

\subsection{Knowledge management of craft technique}

Knowledge management and transfer of craft technique are popular topics in information systems. The majority of cases fall into the scope of industrial and organizational settings of art, creation and innovation industries which value organizations' competitiveness and market performance [18,22,27]. Research on knowledge management of traditional crafts, however, are quite limited with but a few substantial works reported (e.g., [17,35,36]).

The understanding of craft knowledge has primarily been achieved through reflective interactions during the creation process [29], or through master-apprentice relations [6,17] involving a high degree of tacit knowledge, which is externalized only in actions [24]. Practitioners often face a challenge communicating their craft knowledge verbally as this knowledge was internalized without words.

To share knowledge, four modes of knowledge conversion have been considered [22]. For example, Smith et al. [30] explored the possibilities of viewing gestures as an expression of a craft to capture performance of craft skills. They investigated sonification of performative gestures during craft making to depict insights into the practices, rather than analyzing what was made and descriptions of the creation process.

For craft technique externalization [22], researchers have demonstrated transferability of the tacit technique by digital means $[1,17,35,36]$. For example, Wood and her colleagues [17] recorded and transmitted the skilled knowledge of wood carpenters using multimedia, based on the concept of bridges. Aytekin [1], by applying participatory design, investigated a digital platform as means of facilitating knowledge transfer of Turkish local crafts. Knowledge management of craft technique has a huge potential to support endangered craft skills and knowledge.

\subsection{System design for and with craftsmen}

In an introduction of a technological solution to the traditional craft skill transfer, one of the core challenges is technical and organizational acceptance [8] among craftsmen. Thus, finding how to involve craftsmen, who are the single owner of the targeted tacit knowledge, to collaborative prototyping [3] was one of the critical challenges.

Participatory design $[7,14]$ is practiced through participation of challenge-owners or end-users to design information systems. Previously, participatory design has been conducted among various groups of people $[2,12,20]$ in various intercultural settings $[1$, $26,33,34,39]$. For example, Winschiers and her team identified different communication codes which were embedded in Namibian users' culture, which required culture-driven system design $[33,34]$. Similarly, Irani [11] suggests postcolonial computing as an analytical orientation to bring sensibility to the process of design in information systems, having investigated various design cases in developing countries' cultural settings.

This formulates the current discourse on knowledge management systems which advocates considering cultural contexts as an appropriation of the system design process $[18,27]$. It is also natural to assume that similar considerations have to be made in order to design knowledge management system with craftsmen. As different from modern corporate settings, traditional craftsmen are known as people who work alone, keep to themselves, and interact less with other people $[35,36]$. They often hesitate to get special attention from the mass media or have videos and photos taken of them. Japanese craftsmen are noted for their stubborn but honest attitude and are known to be serious about improving their skills. Their relations with superiors and other colleagues are somewhat different from the typical notion of the Japanese organizational hierarchy in which the younger invariably obey the seniors' orders [22]. Experienced 
craftsman believes in their own skills and intuitions and make their own judgments. In accepting something new, they do so to improve their skills rather than to acquire power or influence. Thus, in introducing a knowledge management system into a traditional crafts industry, participatory design could be one of the feasible approaches to meet a socio-technical agenda.

\section{Case}

Company A is a more than 100 years old SME, handling traditional metal casting techniques in Tokyo, Japan. Its molding technique makes it possible to develop fine and sophisticated shapes with high granularity and subtle texture. Company A conducts small/multiple volume production with a total of 20 employees among which 17 are craftsmen. The company is engaged in production as a subcontractor with larger companies in the building materials and automobile industries and their final products are used in cars or buildings. They also provide custom-made products as well as unique hand-manufactured products such as handles, and keys used in traditional temple, shrine, and house architecture. Company A specializes in sand casting with sand molds. In their sand casting, metals are cast into shapes by melting them and pouring them into sand molds that are built in an embedded mold in a wet sand pile. When the metal hardens as it cools, the mold material or casting is removed.

Japanese SMEs such as Company A often specialize in niche techniques that require domainspecific knowledge. Since they use experience intensive techniques that are hard to copy, the industry has enjoyed a leading position in the market for a long time. However, at the same time, it is a labor-intensive work process with a harsh working environment. They have refrained from modernization and digitalization. Limited digital means as well as low Information Communication Technology (ICT) usage in the factory is one of the characteristics of Japanese traditional SMEs [21][11]. Company A recently introduced a Business Process Reengineering (BPR) system. Their BPR does not cover product process management as the majority of their product processes requires experienced knowledge internalized within each craftsman. Moreover, according to the manager, the production would not be sustained without the tacit knowledge and intuition accumulated during the craftsmen's long experiences in metal casting practices.

\subsection{Setting and approach}

Company A has faced the challenge of succession of specialized skills due to lack of new personnel and their aging work force. The Company's manager sought ICT solutions and contacted one of the authors, who is a university researcher. After some discussions, the authors and Company A decided to collaborate to solve the problem by involving craftsmen and managers in system design. This participatory approach was new to them but became a critical concept as it indicated that all parties had to contribute their own skills and knowledge to create new solutions. During a period of seven months from June to December 2015, this system design project was conducted. It started with a field observation of craftsmen in the foundry. It then ran several participatory workshops and ended with the development of a knowledge sharing system prototype.

\subsection{Design and process}

In the project, data collection, workshops and a prototype development were conducted together with the stakeholders as shown in Table 1. It started with preliminary interviews and later field observations with all craftsmen of Company A. The data collection was conducted together with a team of university students who took the author's qualitative research program. In total, 12 hours of video data, 12 hours of voice data, and about 600 photos were collected $([10,37])$.

Table 1. Stakeholders for designing T2S2 Participants

\begin{tabular}{cl}
$\begin{array}{c}\text { Data Collection } \\
\text { (Interview \& field } \\
\text { observation) }\end{array}$ & $\begin{array}{c}\text { All 17 craftsmen at foundry, factory } \\
\text { office, personnel rooms, warehouse. }\end{array}$ \\
\hline Workshops & $\begin{array}{l}\text { 10 participants: Management, Chief } \\
\text { of the foundry, Senior and junior } \\
\text { craftsmen, and System vendor }\end{array}$ \\
\hline
\end{tabular}

Based on the collected data, the authors conducted workshops with key stakeholders that included management, the chief of the foundry, craftsmen, and the system vendor. The workshops were conducted three times, starting with concept development of support systems, discussions of functionalities, and refinement of the main concept. Finally, a prototype knowledge management system was developed together by the authors and system vendor and was brought to the foundry for evaluation. The resulting Traditional Skill Transfer Support (T2S2) system aims to support interactive collaboration beyond temporal boundaries.

In the next section, we elaborate the process of data collection and workshops in detail and describe how 
we developed the T2S2 based on the data and design activities.

\subsection{Data collection and workshops}

Through interviews and field observations, the authors depicted and analyzed the process and techniques of casting as well as the performance of the craftsmen. We described key techniques and possibilities for digital externalization of each process and technique. As a result, the casting process in the foundry was described as a linear process of design: modeling, mounting sanding, creating mold, dissolving, casting, breaking, refining and inspecting. The process approved the Chief of the foundry is shown in column of the process and task of Table 2. For each process, we recorded one or a few key techniques from the observers' perspective. It is important to note that people in the foundry from manager to craftsmen thought that some tacit knowledge behind key techniques was difficult to describe in recordable format so that there were no existing descriptions passed down among craftsman in the company.

Based on the data collected in the field, we conducted workshops together with 10 participants. The workshops aimed to seek a way of describing tacit knowledge using digital media. First, authors showed photos and movie clips collected in the field. These captured scenes in which craftsmen worked with techniques in different craft processes. Then, craftsmen, authors and other participants analyzed and categorized the data together by using an analytical method inspired by grounded theory [5]. More precisely, crafts techniques and tacit knowledge were classified into concepts, element and keywords, then condensed and tagged with the four types, which are naturally equivalent with media types such as document, pictures, movies and on-site (Situ).

1.Document: learn from descriptions and words such as documents

2.Pictures: examine, draw and refer with visual representations such as pictures

3.Movies: imitate techniques by referring to motion pictures such as short video materials

4.Situ: acquire techniques by practicing iteratively in the field by interacting with peers

Table 2. Casting Technique \& Media Use

\begin{tabular}{llcccc}
\hline Process & Key technique and tacit & \multicolumn{4}{c}{ Media } \\
\cline { 3 - 6 } task & knowledge & Do & Pic & Mo & Situ \\
\hline Design & $\begin{array}{l}\text { Define dimension of the } \\
\text { model. Calculate }\end{array}$ & $\mathrm{X}$ & $\mathrm{X}$ & $\mathrm{X}$ & $\mathrm{O}$ \\
& $\begin{array}{l}\text { dimensions by predicting } \\
\text { the shrinking and metal }\end{array}$ & & & & \\
\end{tabular}

\begin{tabular}{|c|c|c|c|c|c|}
\hline & flips. & & & & \\
\hline $\begin{array}{l}\text { Model- } \\
\text { ing }\end{array}$ & $\begin{array}{l}\text { Consider the appropriate } \\
\text { depth, height and length of } \\
\text { the ditch for separating } \\
\text { impurities or floats in the } \\
\text { later process. }\end{array}$ & 0 & $\Delta$ & $x$ & $\Delta$ \\
\hline Form & $\begin{array}{l}\text { Form mold. Define and } \\
\text { adjust moisture and } \\
\text { temperature level by } \\
\text { sensing by hand. }\end{array}$ & 0 & $\mathrm{x}$ & $x$ & $\Delta$ \\
\hline Mold & Achieve ease of casting. & $\Delta$ & $x$ & $x$ & $\Delta$ \\
\hline $\begin{array}{l}\text { Metal } \\
\text { dissolu- } \\
\text { tion }\end{array}$ & $\begin{array}{l}\text { Calculate timing of } \\
\text { dissolution and balance of } \\
\text { ratio of ingredients. }\end{array}$ & $\Delta$ & $\mathrm{x}$ & 0 & $\Delta$ \\
\hline Casting & $\begin{array}{l}\text { Pour melted metal with } \\
\text { fewer bubbles. }\end{array}$ & $x$ & $\mathrm{x}$ & 0 & $\Delta$ \\
\hline Break & $\begin{array}{l}\text { Break molds without } \\
\text { damaging the casting by } \\
\text { paying attention to } \\
\text { direction, projection and } \\
\text { power distribution. }\end{array}$ & $\Delta$ & $x$ & $x$ & 0 \\
\hline $\begin{array}{l}\text { Finish- } \\
\text { ing }\end{array}$ & $\begin{array}{l}\text { Design original and } \\
\text { handmade jigs for } \\
\text { adjusting polishing and } \\
\text { finish. }\end{array}$ & $\Delta$ & $x$ & $x$ & 0 \\
\hline $\begin{array}{l}\text { Inspec- } \\
\text { tion }\end{array}$ & $\begin{array}{l}\text { Quality assurance. Decide } \\
\text { acceptance level of minor } \\
\text { cracks and frost on surface. }\end{array}$ & $x$ & $\Delta$ & $x$ & $\Delta$ \\
\hline
\end{tabular}

The results of the analysis session are as shown in Table 2. Contrary to craftsmen's common belief, certain knowledge could actually be expressed in digital media. Some can be externalized in documents, and others are easier to convey in images or videos. There are also some skills which require traditional master-apprentice learning. For example, the first process, design, is defined as knowledge inherited only through in Situ training. The dimensions of the design drawing of the model have to include the angle (taper) which make it easier to cast, the shrinking allowance which occurs in the process of metal solidification, and machining allowance by which parts are polished out later in depth for evening the surface of the finish. They can be predicted but are difficult to reflect in the design without having in-depth knowledge of and experience with each casting process. Thus, only experienced craftsmen can decide the size by taking all possible influence factors into consideration. This type of skill largely depends on experience and intuition, so that the craftsmen in the workshop agreed learning by doing through interacting with masters (Situ) is regarded as a suitable approach.

In the next workshop, different employees attended and discussed design and functions of the system. First, the key values of the system were identified through discussion. The identified core values in the future 
system were feasibility, usability, and economic efficiency of the knowledge management system maintenance. At the same time, it was emphasized that the system should support the succession of important skills without disturbing daily work. This practical viewpoint was critical together with high usability, as the system was expected to be operated by a small number of craftsmen.

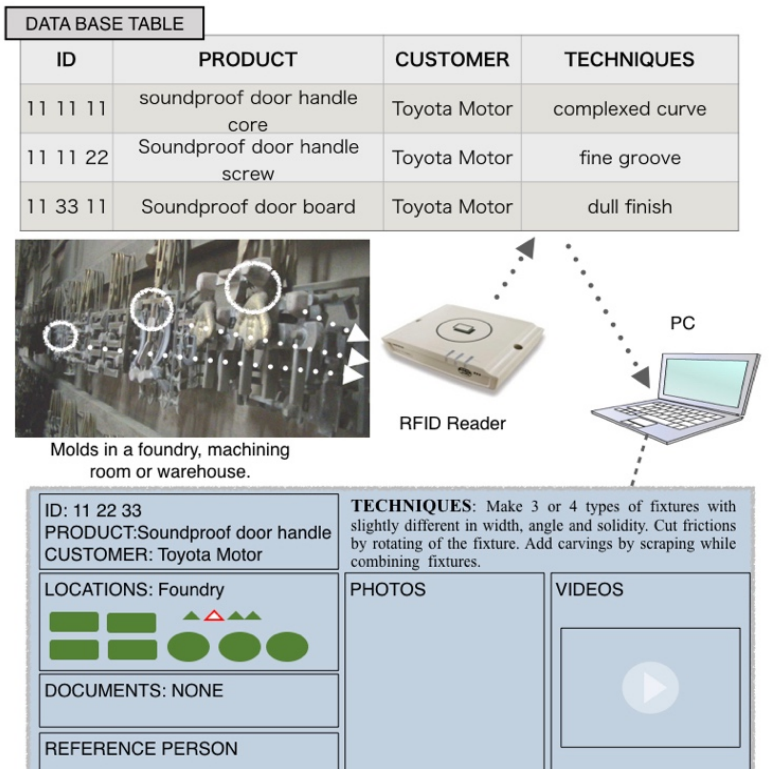

Fig. 1. Image of the System, T2S2

As a result of the workshop discussion, a knowledge management system, T2S2, was proposed. T2S2 is a simple but highly accessible database system. Craftsmen with limited ICT proficiency can easily register extracted tacit knowledge and techniques with the optimal media formats, and easily retrieve such knowledge data. The system refers to Company A's knowledge database, in which related inheritance methods and techniques are accumulated in different media formats such as documents, photos, and video clips. Data in different media formats is automatically displayed and supports the casting process when craftsmen ponder ways to use molds or other tools.

To achieve easy access and retrieval in T2S2, a Radio-frequency identification (RFID) solution was chosen. The system works as shown in Fig. 1. Simply explained, when the RFID reader receives signals from RFID tags, the related information such as skills and knowledge of a process $\mathrm{X}$ and a mold $\mathrm{Y}$ are displayed on the computer screen in a semi-automated way. The adaptation of RFID was an economic choice because there are hundreds of molds in the foundry. At the same time, compared with barcodes, RFID tags are more resistant to water, heat, pressure, and hard to peel off. There is no risk of information leakage as the RFID system does not require internet connection and the suggested system is off-line. The data is only searchable via the RFID reader and displayed on personal computers in the foundry.

In the third workshop, a partially-functional prototype system was installed in the workspace and a user test was conducted. Craftsmen and managers were more relaxed in the third workshop, expressing their opinions and suggesting a few potential ideas concerning the system applications and functions. For example, the below were comments from the craftsmen in the third workshop.

RFID tags ought to be attached not only to molds, but also toggles and tools. In addition, the function to accumulate extra instructions should be deployed. (Craftsman N)

This is a very useful tool as it can visually show the production process and its critical know-how in different ways (pictures and short clips). I believe this would be valuable for educating new employees. (Craftsman A)

The system was tested and discussed by craftsmen, managers, and office workers, based on ISO/IEC 25010 , looking at areas such as functional suitability, reliability, security and usability. Through the user test, a few challenges and suggestions were proposed (See Table 3). Some challenges that required in-depth domain knowledge came to light. Some suggestions for improving the system were made from a practical point of view. New ideas and functions were suggested. In addition, the craftsmen proposed a meta design for the system, which could contribute to the future knowledge system design for skill training of the next generation, with better and easier intuitive communicative means.

\section{Table 3. Examples of suggestions}

\begin{tabular}{cl}
\hline Overlap & $\begin{array}{l}\text { The multiple molds were stored and stacked at one } \\
\text { location on the shelf. It was difficult to identify which } \\
\text { RFID tag information was displayed. }\end{array}$ \\
\hline \multirow{3}{*}{ Obstacles } & $\begin{array}{l}\text { When there was thick metal between the RFID tag } \\
\text { and the reader, the RFID data could not be identified. } \\
\text { It was essential that the molds were organized on the } \\
\text { shelves without the tags being blocked by iron plates. }\end{array}$ \\
\hline Mainte- & $\begin{array}{l}\text { RFID tag could be caught in the machine or removed } \\
\text { in the production process by accident. This indicated } \\
\text { a need for RFID tag maintenance such as retagging at } \\
\text { an appropriate time and checking the correctness of } \\
\text { the component tagging from time to time. }\end{array}$ \\
\hline \multirow{2}{*}{$\begin{array}{l}\text { There were several molds that had no space to mount } \\
\text { Rpace }\end{array}$} & $\begin{array}{l}\text { RFID tags. It was necessary to devise } \\
\text { countermeasures such as putting molds in a bag with } \\
\text { an RFID tag. }\end{array}$ \\
\hline
\end{tabular}

\section{Discussion}

The aim of this research was to design a computational means to support knowledge transfer 
beyond temporal boundaries. Through the craftsmen's collaboration in design, traditional techniques of metal casting were externalized and captured in the knowledge management system. The resistance from practitioners was initially strong and the craftsmen expressed many negative opinions about the use of ICT in their foundry before the workshops. The majority of craftsmen had a strong belief that their techniques were not suitable to verbal or visual expression and thus difficult to support with digital means.

\footnotetext{
"Yes, I am confident in my skills. But as you know, I cannot explain my skills in words. It is fine for me as our clients and my family will see how good our skills are when they see our products embedded in cultural heritages or in a part of their products. (Craftsman A)"
}

The Craftsmen did not imagine that their skills and knowledge could be externalized due to the difficulty of articulating craft knowledge. They believed their skills would be understood in the long run since their long-lasting products could show the artisanal skills behind the products. The Craftsmen also expressed their honest opinion that they were not comfortable about digitizing their skills and sharing them with peer colleagues.

"I make my own jigs at my own expense. Why? I want to express exquisite elegant curves with my skills and tools. I will not reveal my know-how to others as I do not want to lose work (Craftsman C)"

Despite all these negative comments, the craftsmen eventually developed positive attitudes e.g. by making self-initiated design proposals. We discuss this change of mindset of craftsmen and what it means to design a knowledge management system together with people at stake from the following perspectives: Chemistry of Technology and Tradition, Computational Alternative, and Knowledge Management, and Trust.

\subsection{Chemistry of Technology and Tradition}

People tend to think traditional craft techniques and modern digital technology have conflicts. In addition to well-known barriers of knowledge sharing [27], this is likely to be one of the main reasons why traditional industries are hesitant introducing ICT in their work environment. Not only due to job security [25,32], and lack of familiarity to technology [28], but because craftsmen believe their skills are difficult to digitize $[1$, $6,37]$.

In our case, we developed the knowledge management system, T2S2, together with hesitant craftsmen through participatory workshops. The craftsmen committed and improved the system in the workshops and experienced that certain craft skills and techniques could be externalized and conveyed sufficiently through a multimedia system. They also realized there were only few skills and techniques that could be taught only through conventional field practice. T2S2 deploys RFID, which is neither advanced technology nor expensive functions. The system does not require any special skills to use, but only requires intuition and their familiar computer knowledge. This made it possible for the craftsmen to imagine that the system could be integrated into their own work process with confidence.

Providing the overview of the casting process was another advantage brought by the system. Craftsmen in the foundry have their own process in charge such as mold making, polishing, etc. They have a division of labor and individual knowledge is not shared to their peer craftsmen. Thus, even an expert in a certain process does not know how other processes are carried out. When the craftsman used our T2S2, they could access other's knowledge easily so that they could allocate their own task within a whole process for the first time. This became a strong advantage for the craftsmen to improve their skills

Technology and traditional techniques are often regarded as a bad match. However, our case exemplified that appropriate media choice relieved anxiety, achieved trust, and amplified the benefits of technology use. Such an unexpected positive surprise changed the practitioners' perspectives of the system. Such benefits of utilization of multimedia on craft skill transfer were also reported in other cases $[1,17]$. They indicate there is a fit between technology and tradition, and what critical is to think how to choose appropriate media to express knowledge.

\subsection{Computational alternatives}

Contrary to our initial expectations, the craft practitioners accepted recording of their performance, and sharing their skills and techniques in tool usage in words, photos and videos. They participated in design sessions proactively and proposed many ideas with original functions, and designed support systems collaboratively and cooperatively in their own way. Why did this happen?

First, in contrast to traditional craftsmen, modern craft practitioners are accustomed to taking and appearing in photos and video due to the wider use of smartphones in society $[1,17,36]$. Although current craft practitioners work in traditional industries and their workplace has less technology than other industries, their private life is modernized as much as other parts of the digital world. Modern craftsmen do not seem to have much resistance to sharing activities. 
In our case, they enjoyed seeing themselves in photos and videos which reflected their performance out of pure curiosity. They even invited others to see their captured performance.

In the collaborative interactive workshops, the craft practitioners browsed pictures and videos iteratively, reflected frequently on their performance, and suggested improvements of the videos.

"Next time, I will perform like this so that my hand angle will be clearer so that the striking process is more visible to the viewers. It becomes clearer... yes, I think so. (Craftsman, Mr. D)"

Performance in documents, photos and videos were reviewed by the craftsmen using T2S2. By visualizing performance, back-talk [29] occurred and the system worked as a reflective tool $[1,9,35]$. It is interesting to think that initially, the craft practitioners did not have any intentions or expectations regarding the use of multimedia materials. However, through interacting with $\mathrm{T} 2 \mathrm{~S} 2$, they realized that their own videos and photos captured their skills more clearly than they had imagined before. Later, by looking at and trying out the prototype, the craftsmen recognized, probably for the first time, the vast potential of digital tools as means of support tools for their daily work and for knowledge transfer to future generations.

Korsgaards et al. [14] calls workable prototypes, as computational alternatives, which "elucidate problems that otherwise are taken for granted" as "a technical and social design alternative that challenges existing socio-technical conceptions of technology, how it is designed, implemented and used to support practices." In our case, a simple but interactive prototype helped to demonstrate the concept and potential of technology. This elucidated benefit of the system implementation and indicated possibilities to support improvements of their day-to-day practice. Although it was a simple prototype with only fundamental functions and limited skill knowledge coverage, it showed a working system, so that even craftsmen who were not familiar with such digital tools could easily imagine a future with the prototype. Our experience indicates that craftsmen in the traditional craft domain are not necessarily hesitant about visualization, sharing or collaboration regarding their knowledge, if they can understand it doesn't misrepresent their work, and recognize their own benefits, necessity and practical feasibilities.

\subsection{Knowledge management and trust}

We learned from the interviews that Japanese metal casting craftsmen are sometimes hired from another neighboring foundry for a certain period, and at other times they cooperate with other small foundries. This happens since the small foundries cannot afford to integrate many craftsmen into one process of expertise and sometimes have to suffer a situation in which no one is in charge of a certain process. In such a situation, one can imagine that they must share knowledge and collaborate with each other.

However, the situation we experienced initially was different. Before the introduction of T2S2, in Company A, each craftsman only knew the process he or she was responsible for, including its progress, mold types, and location of jigs. It was clear in the observation, as craftsmen stopped working frequently to ask for molds and jigs from others. Moreover, they checked on who did which process and how the progress happened by walking around the foundry. Although they have daily meetings to share information and progress in the morning and evening, they hardly shared key information.

The craftsmen insisted that they usually work independently in a foundry. They also mentioned that they might cooperate with other small foundries, but they draw a clear line about what knowledge to share. They never disclosed their own know-how and never intervened in others' territory. They were proud of their work and committed to their own designated tasks and roles. They were negative about sharing knowledge and externalizing the casting processes as if sharing was forbidden. Consequently, casting knowledge was distributed among craftsmen, and internalized individual knowledge remained inaccessible to peers. It is quite understandable that such a mindset existed. The craftsmen were reluctant to show their valuable skills and share with others, as skills had been critical assets for keeping their professional position in their unique work environment.

To our surprise, despite such craftsmen's comments collected before the workshops, almost no craftsmen were hesitant about sharing their knowledge in the end. Although it is difficult to argue based on our limited data, we would argue our interactive workshops nurtured a sharing and collaborating mindset among practitioners and empowered their professionalism through sharing. A craftsman who was interested in viewing the photos and videos displayed in T2S2, said "I understand the importance of knowledge transfer to other people in a visible and communicative way. If so, correct knowledge should be transferred to contribute to the domain prosperity". This comment indicates that the craftsman reflected on their own high expertise level by watching themselves, and recognized benefits of sharing and collaborating with peers. In the end, craftsmen, who stubbornly emphasized the importance of accumulating many years of field experience and 
did not buy into the idea of digitalized knowledge management, not only accepted the concepts but also became positive supporters and promoters of the design idea.

Through discussion over technology and tradition, benefits of computational alternative, and knowledge sharing attitude of craftsmen, trust towards T2S2 emerged as one of the key factors of knowledge management system design of traditional craft domain. The craftsmen changed mindset as they gained trust in T2S2 as it didn't misrepresent their work, or misuse their contributions, and it benefitted them in improving their own skills.

\section{Conclusion}

In this paper, we introduced a design case of a knowledge management system that supports craft practitioners' knowledge sharing beyond temporal boundaries. The craftsmen in the metal casting foundry, and the authors conducted participatory workshops to design the tacit knowledge management system called T2S2. The workshops were formulated based on the data from field observations and interviews to understand the background of their tacit knowledge. Finally, T2S2 was tested and evaluated.

Generally, Japanese craftsmen do not externalize their performance in words and illustration and hesitate to share their own skills with others. Their work environment is less integrated with technical support systems, and craftsmen see little value in utilizing such technologically enhanced systems in their workplace. In our case, interest in utilizing a knowledge management system in the process of their work was very low at the initial stage, and they were not enthusiastic about the idea of implementing a system in their foundry. However, the craftsmen's mindsets transformed through participatory practice. During the workshops, the craftsmen started to propose additional functions and refine suggestions so that their knowledge and skills were transferred correctly to others. We argue this mindset change occurred because craftsmen gained trust in the T2S2 as they started to see the potential of their skills being inherited by the next generation with the help of digital technology.

This research is one example of designing a knowledge management beyond temporal boundaries, in which Japanese craftsmen acquired confidence in their own work value through the process of collaborative design. By externalizing and visualizing their own work process, the craftsmen recognized their performance, and recognized and confirmed their skill and knowledge value within their cultural context. Their reflection led to their mindset change, which increased peer-to-peer collaboration among craftsman. The confidence made them take ownership of the system, made them proactive in collaboration in their own way, and nourished trust in T2S2.

This work has some clear limitations. The work targeted at a Japanese case, and collaboration in different socio-cultural communities might call for different styles of analysis. We also face a challenge of choosing appropriate media outlet to describe each skill, because tacit knowledge can be conveyed in various forms. One critical necessity is to explore the use of varied media and possible technology in depth to match the form of knowledge. Also, the extracted and implemented tacit knowledge are rather limited and not fully functioned in T2R2 after the evaluation. We have currently in the process of establishment on wider collaboration network with factories and small workshops that valued our results with Company A. Our presented work is the first step to develop a knowledge management system for the metal casting industry, and we aim this next step as future research.

\section{References}

[1] Aytekin, B. A. and K. Rizvanoğlu. 2019. Creating learning bridges through participatory design and technology to achieve sustainability in local crafts. In. Technology and Design Education 29, 3: 603-632.

[2] Branco, R. M., J. Quental, and Ó. Ribeiro. 2016. Playing with personalisation and openness in a codesign project involving people with dementia. In $P D C, 61-70$.

[3] Bratteteig, T. 1997. Mutual learning; Enabling cooperation in systems design. In IRIS, 1-18.

[4] Clark, H. H. 1996. Using Language. Cambridge University Press.

[5] Corbin, J. and A. Strauss. 2008. Basics of Qualitative Research: Techniques and Procedures for Developing Grounded Theory. Sage.

[6] Dumasari, L., W. Darmawan, et al.. 2019. Development of Production Creativity among Craftsmen by Identifying Techniques for Characterizing Coconut Waste. International $J$. on Advanced Science, Engineering and Information Technology 9, 2: 717-723.

[7] Ehn, P. 1992. Scandinavian Design: On Participation and Skill. In Usability, Paul S. Adler and Terry A. Winograd (eds.). 96-132.

[8] Ehn, P. and M. Kyng. 1991. Cardboard computers: Mocking-it-up or hands-on the future. In Design at Work: Cooperative Design of Computer Systems. 169-195. 
[9] Hawson, T. 2006. Contemporary Craft in Iceland : Communicating Culture Through Making. Buckinghamshire Chilterns University College Brunel University.

[10] Hirata, S. and M. Yasuoka. 2018. Consideration on Value Co-creation System for Inheriting Conservation Techniques. International Journal of Automation Technology 12, 4: 553-563.

[11] Irani, L., J. Vertesi, P. Dourish, et al.. 2010. Postcolonial Computing: A Lens on Design and Development. In CHI '10, 1311.

[12] Kanstrup, A. M. 2016. Bringing New Voices to Design of Exercise Technology : participatory design with vulnerable young adults. In $P D C, 121-130$.

[13] Keysar, B., D. J. Barr, et.al. 1998. Definite Reference and Mutual Knowledge: Process Models of Common Ground in Comprehension. J. of Memory and Language 39, 1: 1-20.

[14] Korsgaard, H., C. Nylandsted, and S. Bødker. 2016. Computational alternatives in participatory design - Putting the $\mathrm{T}$ back in Socio-Technical research. In PDC 71-79.

[15] Kyng, M. 1995. Making representations work. Communications of the ACM 38, 9: 46-55.

[16] Larsen, L., A. Bacon, R. Hoppenbrouwers, and K. Borchersen. 2008. The European Qualifications Framework for Lifelong Learning (EQF). Copenhagen.

[17] Lassen, U. H. and N. Wood. 2013. "Plumb line scribe": using multimedia to preserve traditional craft skills. Craft Research Journal 4, 1: 31-52.

[18] Latilla, V. M., F. Frattini, et al.. 2019. Knowledge management and knowledge transfer in arts and crafts organizations: evidence from an exploratory multiple casestudy analysis. Journal. of Knowledge Management.

[19] Lave, J. and E. Wenger. 1991. Situated learning: Legitimate peripheral participation.

[20] Makhaeva, J., C. Frauenberger, and K. Spiel. 2016. Creating Creative Spaces for Co-Designing with Autistic Children. In $P D C$, 51-60.

[21] Ministry of Economy Trade and Industry. 2016. White Paper on International Economy and Trade 2016.

[22] Nonaka, I. and H. Takeuchi. 1995. The Knowledgecreating Company. Oxford University Press.

[23] Otake, H. and Y. Futagami. 2004. Training for a coservator-restorer in western countries: Qualification of restorer of cultural properties in Italy. Preservation Science, 43: 133-145.
[24] Polanyi, M. and S. Amartya. 2009. The Tacit Dimension. University of Chicago Press.

[25] Probst, G., S. Raub, and K. Romhardt. 2001. Managing knowledge-Building blocks for success. John Wiley \& Sons.

[26] Puri, S. K., E. Byrne, J. L. Nhampossa, and Z. B. Quraishi. 2004. Contextuality of Participation in IS Design : A Developing Country Perspective. In PDC: 42-52.

[27] Riege, A. 2005. Three-dozen knowledge-sharing barriers managers must consider. J. of Knowledge Management, 3: 18-35.

[28] Ruddy, T. 2000. Taking knowledge from heads and putting it into hands. Knowledge and Process Management 7 , 1: $37-40$.

[29] Schön, A. D. 1983. The Reflective Practioner: How Professionals Think In Action. Ingram Publisher Services, New York, USA.

[30] Smith, T., S. J. Bowen, B. Nissen, J. Hook, A. Verhoeven, J. Bowers, P. Wright, and P. Olivier. 2015. Exploring Gesture Sonification to Support Reflective Craft Practice. 67-76.

[31]The Royal Danish Academy of Fine Arts and Conservation Schools of Architecture Design. 2017. Insitutute of Conservation.

[32] Tiwana, A. 2002. The Knowledge Management Toolkit: Orchestrating IT, Strategy, and Knowledge Platforms (2nd Edition).

[33] Winschiers-Theophilus, H., S. Chivuno-Kuria, G. K. Kapuire, N. J. Bidwell, and E. Blake. 2010. Being Participated - A Community Approach. In PDC, 1-10.

[34] Winschiers, H. 2006. The Challenges of Participatory Design in a Intercultural Context: Designing for Usability in Namibia. In $P D C, 73-76$.

[35] Wood, N. 2006. Transmitting craft knowledge : designing interactive media to support tacit skills learning.

[36] Wood, N. 2014. Silent witness , using video to record and transmit tacit knowledge in creative practices. In Between craftspersons, University of Gothenburg, 56-69.

[37] Yamaguchi, Y., S. Odajima, et.al.. 2016. Value Creation and Productivity Improvement by Succession of Skills. In Japan Association for Management Systems, 138-139.

[38] Yasuoka, M. 2015. Collaboration Across Professional Boundaries, Journal of CSCW, 24:253-276.

[39] Yasuoka, M. and R. Sakurai. 2012. Out of Scandinavia to Asia - Adaptability of Participatory Design in Culturally Distant Societies. In PDC, 21-24. 